\title{
Author Correction: Noradrenergic signaling in the wakeful state inhibits microglial surveillance and synaptic plasticity in the mouse visual cortex
}

Rianne D. Stowell (D), Grayson O. Sipe, Ryan P. Dawes, Hanna N. Batchelor, Katheryn A. Lordy, Brendan S. Whitelaw, Mark B. Stoessel, Jean M. Bidlack, Edward Brown, Mriganka Sur (D) and Ania K. Majewska (D)

Correction to: Nature Neuroscience https://doi.org/10.1038/s41593-019-0514-0, published online 21 October 2019.

In the version of this article initially published, bars indicating the means in Fig. $1 \mathrm{j}$ were drawn incorrectly, although the individual data points and $P$ value were correct. The error has been corrected in the HTML and PDF versions of the article.
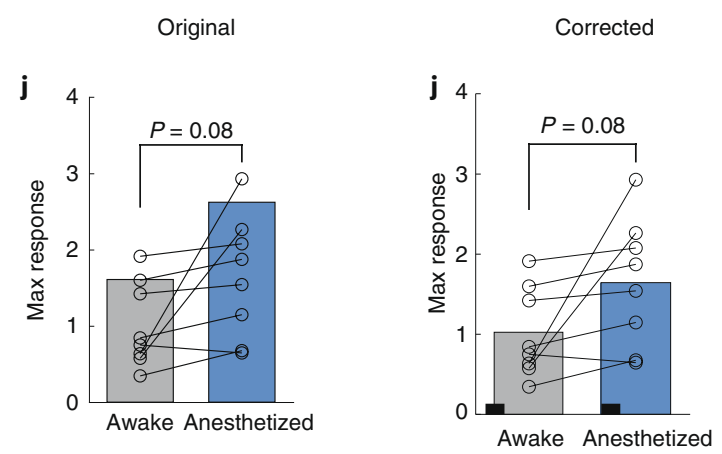

Fig. 1 | Original and Corrected. 